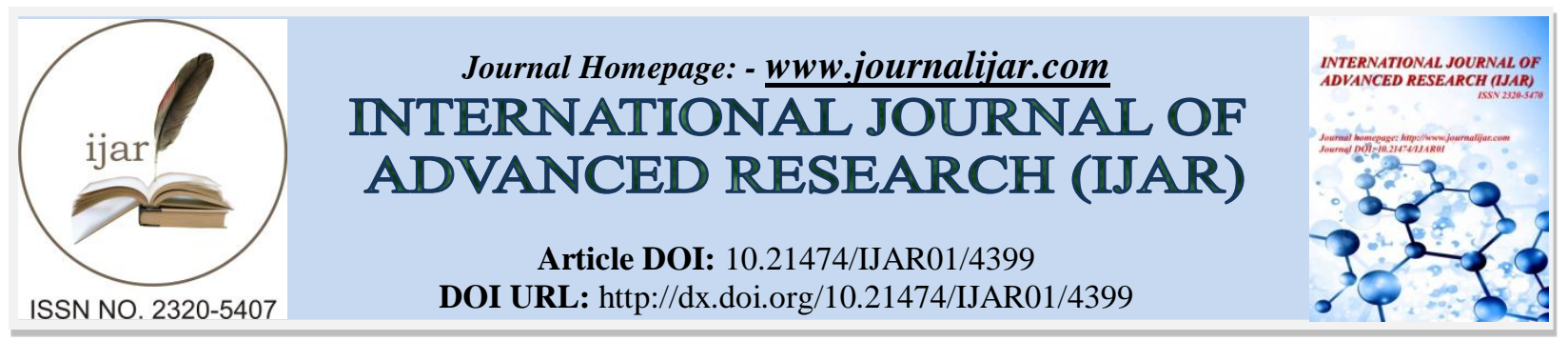

RESEARCH ARTICLE

\title{
ROLE OF SERUM NATURE ON IN VITRO GROWING OF PLASMODIUM FALCIPARU.M.
}

\section{"Kipré Gueyraud Rolland ${ }^{1}$, BAGRE Issa ${ }^{1}$, Bla Kouakou Brice ${ }^{1}$ and Djaman Allico Joseph ${ }^{1,2}$.}

1. Laboratoire de Pharmacodynamie-biochimique, UFR Biosciences, Université de Cocody, 22 BP 582 Abidjan 22.

2. Laboratoire de biochimie, Institut Pasteur de Côte d'Ivoire, Bp V 490 Abidjan.

\section{Manuscript Info}

(........................

Manuscript History

Received: 06 April 2017

Final Accepted: 07 May 2017

Published: June 2017

Key words:-

In vitro culture, human serum,

Plasmodium antibody, Resistant strain

\section{Abstract}

Plasmodium falciparum, the liable parasite for the mortal malaria, is a major case of morbidness and of mortality in everybody tropical.

The in vitro culture of the Plasmodium remains an indispensable method for determination of the proof phenotype and of the surveillance of the efficacity of antimalarial drugs.

Culture of Plasmodium falciparum requires the use of RPMI 1640 medium, the efficacy of which depends on addition of human serum. Culture with medium containing either reference human serum (RS) or serum containing Plasmodium antibodies (SND) provides a plasmodial maturation rate exceeding $20 \%$ (lower threshold of validity according to WHO). Comparison of these two culture supplements for in vitro testing of the chemosensitivity of Plasmodium strains to pyrimethamine showed no difference in IC50: $<2000 \mathrm{nM}$ for sensitive strains (FCB1 and PFB) and > $2000 \mathrm{nM}$ for resistant strain $(\mathrm{K} 1)$

Copy Right, IJAR, 2017,. All rights reserved.

\section{Introduction:-}

Malaria has been a great challenge to humanity since time immemorial. An estimated 300-500 million people are affected by malaria throughout world annually (WHO, 2012). This same world health organization (WHO) source indicates that $95 \%$ of malaria related deaths occur in sub-Saharan Africa, with children younger than five years of age and pregnant women being the most severely affected.

Despite massive efforts to control malaria, the percentage of morbidity and mortality has not changed significantly over the past 50 years (Greenwood, 2004).

In the control of this parasitosis, in vitro study makes it possible to evaluate the intrinsic sensitivity of parasites to antimalarials and to characterize epidemiologically, the nature of Plasmodium isolates circulating in area (Guigemde et al., 1996).

This study gives the possibility of measuring the efficacy of an antimalarial without interfering factors in multiplication of parasites such as host immunity (Rieckmann and Lopes-Antunamo, 1971).

The cultivation of Plasmodium falciparum requires a culture medium, the RPMI 1640 (Roosvelt Park Medium Institute), the efficacy of which is linked to addition of human serum either without antiplasmodial antibodies or is 
depleted when the serum comes from a living subject in an endemic area (WHO, 1982, Schlichtherle et al., 2000). Indeed, the presence of antiplasmodial antibodies, as well as leukocytes in the blood adds its schizonticidal effects to those of the drug studied in vitro. Plasmodial growth is then impossible as a result of inhibition of young trophozoites (Danis and Mouchet, 1991).

If the serum without antibody is difficult to access because of its high cost, the second type, serum with antibody, requires additional work of decomplementation and sterilization on the millipore filter.

The objective of this work is to evaluate the efficacy of serum containing Plasmodium antibodies (SND) in vitro culture of $P$. falciparum strains relative to reference human serum (RS).

\section{Materials and Methods:- \\ Materials:-}

Three strains of $P$. Falciparum, PFB and FCB1 (resistant to Chloroquine and sensitive to Pyrimethamine) and K1 (resistant to chloroquine and pyrimethamine), as well as healthy red blood cells of group 0+ were used as biological materials. These healthy red blood cells were used to dilute the parasitized blood when the parasitic density was greater than 8000 asexual parasites per microliter of blood.

RPMI 1640 containing $25 \mathrm{mM}$ HEPES and $25 \mathrm{mM}$ sodium bicarbonate (NaHCO3) was used as culture medium for P. falciparum strains. To this culture medium, $10 \%$ of human serum RS or SND is added.

\section{Methods:-}

The strains PFB, FCB1 and K1 stored in liquid nitrogen are thawed and kept in culture (in the absence of antimalarial) for a few days in order to obtain a good parasitic density. Before cultivation in presence of antimalarial, the culture was synchronized by treating blood parasitized with 5\% sorbitol in order to obtain parasite parasites ("ring") only (Lambros and Vanderberg, 1979).

In the first part of the work, the strains are kept in culture in RPS (RPMI depleted in folic acid containing 10\% human serum) in an oven set at $37^{\circ} \mathrm{C}$ in presence of carbon dioxide and $95 \%$ of humidity during 42 hours in a candle jar (Le Bras and Deloron, 1983). The added human serum is RS or SND.

The maturation check is carried out after 42 hours of incubation by counting the number of schizonts per 200 asexual parasites after reading the thick drops obtained from the cultures in absence of antimalarial.

The second part of this work was devoted to pyrimethamine chemosensitivity test using the RS in parallel with the SND to verify the sensitivity of strains to pyrimethamine.

It is the isotopic variant of the OMS microtest that has been used in this work (Rieckmann and López-Antuñamo, 1971). It measures the capacity of increasing doses of an antimalarial to inhibit the growth of Plasmodium in a culture medium (RPMI containing human serum). After 42 hours of incubation, DNA is collected after washing on glass fiber paper with a cell collector, and then the amount of hypoxanthine incorporated by the parasites is measured by a liquid scintillation counter (WALLAC, 1450 Microbeta TRILUX) in a shot per minute. A regression line drawn by a program from these values makes it possible to determine IC50 of each product on the three strains for each type of serum.

\section{Results and Discussion:-}

The reference human serum (RS) added to RPMI 1640 allowed to obtain matures of trophozoites of $P$. falciparum in schizontes greater than $20 \%$ (reference ripening rate to validate in vitro culture) and this, whatever plasmodial strain . This maturation is $83 \%$ for FCB1, $75 \%$ for PFB and $90 \%$ for K1. With serum SND, the ripening rate is $77 \%$ for FCB1, $70 \%$ for PFB and $80 \%$ for K1 (Table 1). 
Table 1: In vitro sensitivity to pyrimethamine of P. falciparum strain according to serum added in culture medium (RPMI 1640)

\begin{tabular}{|c|c|c|c|}
\hline & \multicolumn{2}{c|}{ IC50 $(\mathrm{nM})$ of pyrimethamine $\left({ }^{*} \mathrm{n}=3\right)$} & Test of student $5 \%$ \\
\hline Strains & SR & SND & 0.043 \\
\hline FCB1 & $201.60 \pm 16.90$ & $253.30 \pm 52.74$ & 0.002 \\
\hline PFB & $48.29 \pm 0.04$ & $48.94 \pm 1.34$ & 0.001 \\
\hline K1 & $4805 \pm 643$ & $4877 \pm 562.60$ & \\
\hline
\end{tabular}

$\mathrm{n}:$ number of tests realized

In the analysis of results obtained with SND (77\% for FCB1, 70\% for PFB and $80 \%$ for K1), it appears that serum SND does not present a risk of inhibition of the maturation of plasmodium in vitro culture. It provides results as satisfactory as SR used up until now in in vitro evaluation of the chemosensitivity of $P$. falciparum. The reference rate of growth of young trophozoites in schizonts indicated by the WHO to validate a chemosensitivity test and then to determine the antiplasmodial activity of a substance is $20 \%$ (Schlichtherle et al., 2000). The interest of this study was to obtain at least $20 \%$ of schizonts in cultures without antimalarial and hypoxanthine, which served as controls to launch our isotopic tests and to determine IC50 of the strains against Pyrimethamine on medium containing SND. Indeed, while some authors have demonstrated the role of antiplasmodial antibodies in immunity against asexual blood forms of P. falciparum (Danis and Mouchet, 1991), many studies have attempted to determine the mode of action of these antibodies.

It has been demonstrated on the surface of red blood cells parasitized by P. falciparum, a specific antigen called HRP2 antigen (Histidine Rich Protein 2) which is a glycoprotein with galactose as sugar. The recognition of this protein by antiplasmodial antibodies makes it possible to form a complex which exerts a destructive action on the Plasmodium within the red blood cell.

The series of washing (three times) followed by centrifugation followed by the removal of the buffy coat before cultivation of parasites is intended to remove the HRP2 proteins present on the surface of parasitized erythrocytes required for The binding of antibodies and the formation of the anti-HRP2 antibody complex. At the end of this washing, we obtain red blood cells lacking or weakly provided with HRP2 proteins, Plasmodium can grow normally.

Under these conditions, it is possible with SND to carry out a chemosensitivity test which makes it possible to measure the capacity of increasing concentrations of an antimalarial to inhibit the formation of schizonts (figure 1).

Figure 1:- Rate of maturation in schizontes of $P$. falciparum.

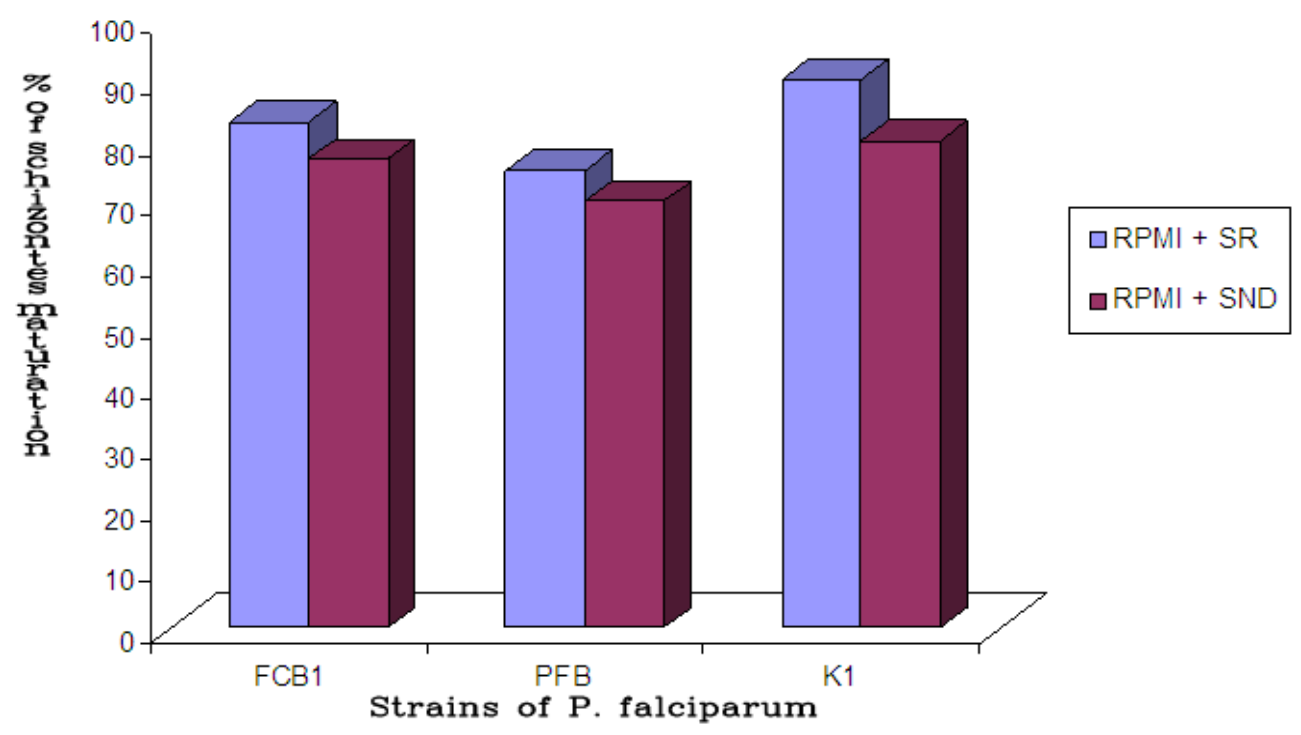




\section{Conclusion:-}

It was possible to carry out in vitro cultures of $P$. falciparum using serum SND. Since malaria is an infectious disease that particularly affects sub-Saharan Africa, the use of SND supplemented with RPMI is to enable south laboratories with means at their disposal to carry out surveillance of $P$. falciparum strains circulating in area. It is also possible to measure the sensitivity of these strains in relation to the usual antimalarials and to allow the systematic screening of new antimalarial substances such as those derived from the traditional african pharmacopoeia (O'Neil and al., 1986).

\section{References:-}

1. Danis M., Mouchet J. 1991. La réponse immune de l'hôte, l'adaptation du parasite et chimiorésistance des Plasmodiums in Paludisme. Ed. marketing : ellipses, 240p.

2. Guiguemde T.R., Gbary A.R., Coulibaly C.O., Ouedraogo J.B. 1996. Comment réaliser et interpréter les résultats d'une épreuve de chimiorésistance de $P$. falciparum chez les sujets malades en zone tropicale. Cahiers sante, $6: 187-191$.

3. Greenwood B. 2004. Malaria : between hope and hard place. Nature, $3: 418420$.

4. Lambros C., Vanderberg J.P. 1979. Synchronization of Plasmodium. Falciparum erythrocytic stages in culture. J Parasitol, $3: 418-420$.

5. Le Bras J., Deloron P. 1983. In vitro study of drug sensitivity of Plasmodium falciparum an evaluation of a new semi microtest, Am J Trop Med Hyg, 32 : 447-451.

6. O'Neil J.M., Bray D. H., Boardman P., Phillipson D. 1986. Plants as sources of antimalarial drugs : in vitro antimalarial activities of some quassinoids. Antimicrobial Agent and Chemotherapy, 30:101-104.

7. Rieckmann K.H, Lopes-Antunamo F.J. 1971. Mode d'emploi du nécessaire d'épreuve pour l'évaluation de la réponse de $P$. falciparum à la chloroquine in vitro. Bull Org Mond Santé, 45 : 157-167.

8. Schlichtherle M., Wahlgren M., Perlmann H., Scherf A. 2000. Methods in malaria research third. Ed. MR4/ATCC Manassas, Virginia USA $2000 ; 77 \mathrm{p}$.

9. WHO. World malaria report 2012. Geneva: World Health Organization; 2013. 